\title{
Uso do Google Sala de Aula no Ensino-Aprendizagem de Anatomia Humana ${ }^{1}$
}

\author{
Mayra Nunes de Freitas \\ Mestranda em Enfermagem pelo Programa de Pós-Graduação Stricto Sensu da Faculdade de Medicina de São José do Rio Preto - FAMERP. Especialista em \\ Biologia e Patologia Celular UNESP (2008.) Graduada em Ciências Biológicas pelo Centro Universitário de Rio Preto UNIRP (2004). Experiência como docente \\ da disciplina de Anatomia e Fisiologia Humana no ensino superior (2013 até o momento) \\ $\bowtie$ mayra.nfreitas@gmail.com

\begin{abstract}
Alexandre Lins Werneck
Mestrado e Doutorado em Ciências da Saúde pelo Programa de Pós-Graduação Stricto Sensu da Faculdade de Medicina de São José do Rio Preto. Professor Doutor do Programa de Pós-Graduação em Enfermagem - Nível Mestrado - da Faculdade de Medicina de São José do Rio Preto - FAMERP - São José do Rio Preto, São Paulo, Brasil

$\triangle \underline{\text { alexandre.werneck@famep.br }}$
\end{abstract}

\section{Luciene Cavalcante Rodrigues} \\ Possui graduação em Tecnologia em Processamento de Dados pelo Centro Universitário de Rio Preto (1998), Licenciatura em Informática pelo Centro Estadual \\ de Educação Tecnológica Paula Souza (2008), mestrado em Engenharia Elétrica (2002) e doutorado em Ciências na área de Física Computacional (2012), ambos \\ pela Universidade de São Paulo, também possui especialização em Design Instrucional para EAD Virtual pela UNIFEI (2010), Didática do Ensino Superior pela \\ Universidade Gama Filho (2010) e Planejamento, Implementação e Gestão da EAD pela UFF (2010). Atua principalmente em processamento de imagens, \\ informática aplicada à saúde, Educação, Jogos, Soluções Web e Computação móvel. Faz parte do grupo de pesquisa Tecnologias e Práticas inovadoras aplicadas \\ ao ensino \\ $\triangle$ prof.luciene@fatecriopreto.edu.br
}

\section{Rita de Cássia Helú Mendonça Ribeiro}

Professora Doutora, Departamento de Enfermagem Geral, Faculdade de Medicina de São José do Rio Preto (FAMERP)

Professora Doutora do Programa de Pós-Graduação em Enfermagem - Nível Mestrado, da Faculdade de Medicina de São José do Rio Preto - FAMERP, São José do Rio Preto, São Paulo, Brasil

$\triangle$ ricardo.rita@terra.com.br

\section{Daniele Alcalá Pompeo}

Doutora, Faculdade de Medicina de São José do Rio Preto (FAMERP), Departamento de Enfermagem Especializada.

Professora Doutora do Programa de Pós-Graduação em Enfermagem - Nível Mestrado, da Faculdade de Medicina de São José do Rio Preto - FAMERP, São José do Rio Preto, São Paulo, Brasil

daniele.pompeo@famerp.br

Recebido em 15 de agosto de 2020

Aceito em 19 de setembro de 2021

\section{Resumo:}

Existe um afunilamento cada vez mais crescente dos limiares entre educação e tecnologias. As mudanças vivenciadas são constantes e rápidas, principalmente nas áreas da comunicação e saúde. É uma pesquisa prospectiva com delineamento descritivo, abordagem quantitativa do tipo analítica com correlação entre variáveis. A análise de dados por meio de questionários e descrevendo as etapas do desenvolvimento e implementação do ambiente virtual de aprendizagem. O estudo foi desenvolvido na Faculdade de Medicina de São José do Rio Preto, no estado de São Paulo. Os dados foram analisados usando-se estatística descritiva, cálculos de frequência e outras medidas que se mostraram importantes no momento da análise. Dos participantes ( $N=12), 75 \%$ já conheciam o ambiente virtual de aprendizagem e 56,25\% conheciam a ferramenta Google Sala de Aula, mas não a utilizavam em suas aulas. Nos questionários, $75 \%$ julgaram que as metas foram alcançadas e $75 \%$ relataram que os conteúdos expostos estavam "dentro do esperado" e "maior que o esperado". Concluímos que o ambiente virtual de aprendizagem é uma ferramenta importante para o ensino-aprendizagem de Anatomia Humana.

Palavras-chave: Anatomia Regional; Aprendizagem ativa; Ensino à distância; Ambiente virtual de aprendizagem; Projeto de Tecnologia de Informação e Comunicação.

\footnotetext{
1 Este artigo foi extraído da Dissertação "Tecnologias da informação e comunicação no ensino-aprendizagem de anatomia humana", apresentada ao Programa de Pós-Graduação Stricto Sensu em Enfermagem da Faculdade de Medicina de São José do Rio Preto, para obtenção do Título de Mestre. São José do Rio Preto, SP, 2020.
} 


\title{
Use of Google Classroom in Teaching and Learning Human Anatomy
}

\begin{abstract}
:
There is an ever-increasing narrowing of the thresholds between education and technology. The changes experienced are constant and rapid, especially in the areas of communication and health. We carried out a prospective research with descriptive design using a quantitative analytical approach with correlation among variables. Data analysis was obtained from questionnaires. We also described the steps of development and implementation of the virtual-learning environment. The study was developed at Faculdade de Medicina de São José do Rio Preto, located in the inland of São Paulo State. We analyzed data using descriptive statistics, frequency calculations, and other measures that proved to be important at the time of the analysis. Of the participants $(\mathrm{N}=12), 75 \%$ already knew the virtual learning environment and $56.25 \%$ knew the Google Classroom tool but did not use it in their classes. We applied all steps of the ADDIE model related to the building training, and performance supported tools. In the evaluative questionnaires, $75 \%$ considered that the goals were reached and $75 \%$ reported that the exposed contents were "within the expected" or "greater than expected." We concluded that the virtual-learning environment was an important tool for teaching and learning Human Anatomy, showing the relevance of a Web-based platform.
\end{abstract}

Keywords: Anatomy, Regional; Problem-based learning; Education, Distance; Virtual Learning Environment; Information Technologies and Communication Projects.

\section{Uso de Google Classroom en la enseñanza y el aprendizaje de la anatomía humana}

\section{Resumen:}

Hay un estrechamiento cada vez mayor de los umbrales entre educación y tecnología. Los cambios experimentados son constantes y rápidos, especialmente en las áreas de comunicación y salud. Realizamos una investigación prospectiva con diseño descriptivo utilizando un enfoque analítico cuantitativo con correlación entre variables. El análisis de los datos se obtuvo de los cuestionarios. Describimos los pasos de desarrollo e implementación del entorno de aprendizaje virtual. El estudio fue desarrollado en la Faculdade de Medicina de São José do Rio Preto, ubicada en el inlando del estado de São Paulo. Analizamos los datos utilizando estadísticas descriptivas, cálculos de frecuencia y otras medidas que resultaron ser importantes en el momento del análisis. De los participantes $(\mathrm{N}=12)$, el $75 \%$ ya conocía el entorno de aprendizaje virtual y el 56,25\% conocía la herramienta Google Classroom, pero no la usaba en sus clases. Aplicamos todos los pasos del modelo ADDIE relacionados con la capacitación del edificio y las herramientas compatibles con el rendimiento. En los cuestionarios evaluativos, el $75 \%$ consideró que se alcanzaron los objetivos y el 75\% informó que los contenidos expuestos estaban "dentro de lo esperado" o "mayor de lo esperado". Llegamos a la conclusión de que el entorno de aprendizaje virtual era una herramienta importante para la enseñanza y el aprendizaje de la anatomía humana, mostrando la relevancia de una plataforma basada en la web.

Palabras clave: Anatomía Regional; Aprendizaje Basado en Problemas; Educación a Distancia; Entorno virtual de aprendizaje; Proyectos de Tecnologías de Información y Comunicación.

\section{INTRODUÇÃO}

Existe uma busca constante de transformar o universo educacional em ambientes motivadores aos estudantes, onde o aluno passa a ser o protagonista do seu aprendizado. (MORAN, 2015) Um dos desafios da educação o repensar sobre novas propostas educativas 
que superem a instrução ditada pelo livro didático, centrada no dizer do professor e na passividade do aluno. E que é importante considerar a cultura digital, marcada pela criação e abertura de limites espaciais e temporais da sala de aula. A exploração dessas características demanda reconsiderar o currículo e as metodologias que colocam o aluno no centro do processo educativo e focam na aprendizagem ativa. (VALENTE, ALMEIDA \& GERALDINI, 2017)

O ensino superior presencial encontra-se em processo de plena hibridização, principalmente após a revogação da Portaria nำ1.134/2016 e a publicação da Portaria nำ1.428, de 28 de dezembro de 2018. Essa portaria dispõe sobre a oferta de disciplinas com metodologia a distância em cursos de graduação presencial, por Instituições de Educação Superior- IES credenciadas pelo Ministério da Educação. A Portaria define em seu artigo terceiro que, a oferta de disciplinas na modalidade a distância poderá ser ampliada para até 40\% (quarenta por cento) para cursos de graduação presencial, desde que as instituições atendam aos requisitos previstos pela legislação vigente. (BRASIL, 2018)

As tecnologias voltadas para a comunicação se mostraram protagonistas de um cenário de inovações e mudanças, nos quais a informação e o conhecimento parecem disponíveis e acessíveis a todos e a todo tempo (ROSENAU et al., 2017). o caminho para o desenvolvimento de tecnologias é a educação. Estados Unidos da América, Inglaterra, Coreia do Sul, dentre outros, investiram na área por entenderem que é necessário instrução para a melhor utilização de recursos para possibilitar a geração de riqueza (GALVÃO, THOMAS e PEREIRA, 2017).

Contudo, sabe-se que essa integração entre Educação e TIC ainda está à margem do estado ideal, porém, novas evoluções são percebidas conforme essa realidade passa a ser uma necessidade para educadores e instituições de ensino que, por consequência, passam a revisar e repensar suas práticas pedagógicas (BACHIC, TANZI NETO, TREVISANI, 2015). Nesse sentido, o preparo do enfermeiro deve ser focado em estar apto a cuidar de pessoas, uma ação que as metodologias ativas possibilitam (OLIVEIRA e COPPOLA, 2017).

A Google Suite for Education (Gsuite) oferece um conjunto de ferramentas de comunicação e produtividade destinadas a promover a colaboração e a criatividade, que incluem: Gmail, Google Docs, Google Drive e Google Sala de Aula. Dentre este conjunto de ferramenta tem-se destacado o Google Sala de Aula, que consiste em uma sala virtual, onde o professor organiza, acompanha, atribui comentários, insere notas para as produções 
realizadas pelos alunos, previamente cadastrados (WITT, 2015). Atualmente existe uma parceria entre a empresa Google e as universidades públicas brasileiras para oferta desse tipo de serviço gratuitamente. Assim, todos os envolvidos no processo educacional desenvolvem a confiança com a tecnologia, possibilitando uma aprendizagem mais significativa no contexto de sala de aula. Em estudos realizados por Schiehl e Gasparini (2016) foi visto que além dos alunos, o professor responsável pela turma pode cadastrar outras pessoas como: o coordenador pedagógico, professores de outras disciplinas, ou até mesmo os pais dos alunos.

Algumas vantagens do uso dessa ferramenta, são elas: fácil manuseio, promove a aprendizagem on-line, auxilia os professores na postagem e recebimento de atividades, dentro e fora da sala de aula, apresenta-se em idioma português, além de ser acessado através de um computador ou smartphone, está interligada ao Google Drive. Possibilita ainda disponibilizar materiais sobre os conteúdos preparados em aula, inserir documentos, formulários, vídeos, apresentações, entre outros. O estudante poderá ver, rever e desenvolver suas atividades a qualquer momento uma vez que esses documentos ficam à sua disposição. Além disso, ele poderá acompanhar seu desempenho bem como o prazo de cada atividade, pois as informações ficam registradas no Google Sala de Aula. Em caso de dúvida em alguma atividade extraclasse, os estudantes poderão entrar em contato com o professor tanto de forma síncrona como assíncrona (SOUSA JÚNIOR et al. (2017).

Portanto, o Google Sala de Aula é uma plataforma que possibilita a interação, organização e a orientação personalizada ao ritmo de estudo do estudante. Pesquisadores relatam que os estudantes se sentem mais motivados com o uso do Google Sala de Aula, e que favorece o aprendizado significativo (DICICCO, 2016).

A Anatomia Humana, além de ser uma disciplina clássica para todos os cursos da saúde, principalmente para o curso de enfermagem, reflete interfaces educacionais que proporcionam grande relação, sendo que seu entendimento é de extrema sobriedade e considerada como pré-requisito para a compreensão das demais disciplinas da graduação (Mourthé Filho, 2016).

A utilização de métodos computadorizados de aprendizagem com o surgimento dos conceitos construtivistas e das Novas Tecnologias de Informação e Comunicação (NTIC) são de extrema importância para o estabelecimento de uma nova dinâmica de relação entre 
professor e aluno pois, orientam e facilitam o entendimento dos conteúdos resultando em uma motivação a mais ao estudo tradicional da Anatomia Humana (SILVA et al, 2017).

O objetivo do presente artigo foi mostrar as potencialidades do Google Sala de Aula como ambiente virtual de aprendizagem no ensino-aprendizagem da Anatomia Humana no curso de graduação em Enfermagem. Os específicos, para subsidiar o Objetivo Geral foram: Analisar se novos métodos de ensino na Anatomia Humana diminui as dificuldades relacionadas à disciplina e proporcionam um melhor processo de ensino-aprendizagem; Observar se o uso do Google Sala de aula como ferramenta didática adicional no ensino da Osteologia impacta no desempenho acadêmico dos alunos no curso de graduação em Enfermagem; Avaliar o efeito do Ambiente Virtual de Aprendizagem (Google Sala de Aula) no desempenho das atividades de estudos de casos clínicos de Osteologia na disciplina de Anatomia Humana pelos alunos do curso de graduação em Enfermagem inscritos na pesquisa; Apresentar algumas formas de utilização da ferramenta Google Sala de Aula no Ensino Superior, como apoio ao ensino-aprendizagem e seus desdobramentos.

\section{METODOLOGIA/ MATERIAL E MÉTODOS}

Desenvolveu-se uma pesquisa prospectiva com delineamento descritivo e abordagem quantitativa do tipo analítica com correlação entre variáveis, utilizando questionários e descrevendo etapas do desenvolvimento e implementação do Google Sala de Aula, com perguntas abertas e fechadas sem identificação do aluno na fase inicial do estudo e, para análise do público-alvo quanto ao perfil social e uso de recursos tecnológicos. A pesquisa foi aplicada em uma instituição de ensino superior de grande porte em São José do Rio Preto- SP.

Esta pesquisa foi aprovada pelo Comitê de Ética e Pesquisa da Faculdade de Medicina de São José do Rio Preto (FAMERP), Parecer nํㅜ 3.090.647.

Os dados foram coletados em período pré-determinado, de 24 de junho a 05 de agosto de 2019, no total de seis semanas, no primeiro e segundo semestre letivo, com duas aulas presenciais - a inicial e a última - e oito módulos na modalidade plataforma Google Sala de Aula, na qual os participantes, mediante orientação quanto ao rigor ético da pesquisa e cumprindo com a Legislação 
vigente de pesquisa com seres humanos, foram comunicados sobre a pesquisa, objetivos, TCLE Termo de Consentimento Livre e Esclarecido, previamente lido, compreendido e assinado mediante o desejo de colaborar com a pesquisa. Foi assegurada a liberdade de não participar da pesquisa, sendo respeitado o direito de recusa.

O critério de inclusão da pesquisa foram alunos da $2^{\text {a }}$ e $3^{\text {a }}$ séries do Curso de Enfermagem inscritos, como voluntários no projeto de mestrado, de uma instituição de ensino superior de São José do Rio Preto, no período de junho a agosto de 2019. Os critérios de exclusão foram alunos que não quiseram participar da pesquisa, ou que não completaram as tarefas envolvidas no estudo, ou terem interrompido sua participação em qualquer uma das etapas.

Para a coleta de dados foram aplicados aos graduandos de Enfermagem da $2^{\mathrm{a}}$ e $3^{\mathrm{a}}$ séries, que se inscreveram para participar da pesquisa de mestrado. A população elegível foi selecionada por amostragem não probabilística em sequência, ou seja, envolveu o recrutamento de todos os alunos de uma população acessível em um intervalo de tempo específico. Inscreveram-se 16 alunos, sendo que quatro desistiram, portanto, a amostra final foi de 12 alunos. Foram aplicados quatro questionários de avaliação. Existem, no munícipio, outros cursos de graduação em enfermagem, porém, nenhum deles permitiu que a pesquisa fosse realizada em suas Instituições.

Para a estruturação do Google Sala de Aula, foi previamente elaborado um plano de ensino para capacitação e os referidos planos de aula dos encontros presenciais e à distância.

Um questionário foi aplicado no período de pré-avaliação, elaborado no Google Forms $^{\circledast}$, para obtenção do perfil da amostra. Aplicamos após a intervenção, um questionário referente à plataforma Google Sala de Aula; um questionário com relação ao modo de acessibilidade do ambiente Google Sala de Aula e, por fim, um questionário da importância da utilização do Google Sala de Aula no ensino-aprendizagem de Anatomia Humana. O período de coleta e utilização do Google Sala de Aula ocorreu de junho a agosto de 2019.

A pesquisa foi desenvolvida em três etapas. Na primeira etapa, fez-se um levantamento de quais alunos fazem o uso do Google Gmail, pois é de suma importância que todos os alunos tenham acesso ao Gmail. Foi apresentada à turma a proposta da experimentação da metodologia Sala de Aula Invertida (SAI) com uso do Google Sala de Aula 
para possibilitar o desenvolvimento da pesquisa. Na segunda etapa do projeto, foi aplicado um questionário disponível via Google Sala de Aula, o que possibilitou aos alunos terem acesso à pesquisa, primeiramente visando investigar o nível de conhecimento em informática dos alunos. Na terceira etapa, ocorreu o teste de usabilidade do Google Sala de Aula. Os participantes receberam orientações e executaram tarefas pré-definidas no Google Sala de Aula.

A carga horária da capacitação foi de 30 horas, divididas entre encontros presenciais e a distância. Houve um encontro presencial inicial (dentre dois presenciais) para elucidar aos participantes sobre a ferramenta Google Sala de Aula e o questionário objetivo para verificar conhecimento e habilidade dos respondentes da pesquisa quanto ao uso da tecnologia e navegabilidade. Em seguida foram determinadas mediante um cronograma, os encontros presenciais para orientações pontuais, plantão de dúvidas, auxílio no manuseio da ferramenta (caso haja dúvidas e/ou dificuldades) e encontros online, operados diretamente no Google Sala de Aula, destinado ao aprendizado sobre as Tecnologias da Informação e Comunicação no ensino-aprendizagem de Anatomia Humana. Foram dois encontros presenciais, distribuídos em início (aula inaugural) para orientações gerais e entrega do TCLE, onde os dados foram coletados por meio de questionário on-line (sem obrigatoriedade da identificação do aluno) na fase inicial do estudo, para análise do público-alvo quanto ao perfil social e uso de recursos tecnológicos, e, por fim, o último encontro presencial para o encerramento das atividades propostas no Google Sala de Aula e aplicação do questionário diagnóstico, questionário este em formato físico (papel e sem identificação do aluno) para avaliação plataforma Google Sala de Aula. Aconteceram oito encontros on-line, por meio do Google Sala de Aula, nos quais foram distribuídas atividades referentes ao estudo de casos clínicos de Osteologia aplicados na Anatomia Humana para que os alunos conseguissem analisar, interpretar os fatos e levar as informações adquiridas para o seu futuro trabalho profissional.

Todos os encontros on-line e presenciais, tiveram as atividades previamente determinadas, descritas e estruturadas visando um design instrucional voltado para a plataforma Google Sala de Aula, favorecendo um processo ensino-aprendizagem dinâmico e participativo, onde os pares pudessem juntos, construir o conhecimento e incorporar o estudo da Anatomia Humana no seu cotidiano profissional. Para tal, foi descrito plano de ensino da capacitação e plano de aula especificando cada encontro presencial e à distância. 
O estudo teve como objetivo coletar dados de forma direta, na qual o pesquisador obteve acesso ao ambiente analisado. Os dados coletados nesse tipo de pesquisa foram descritivos e que relatam os elementos existentes na realidade estudada, sendo que com essa implementação da tecnologia no dia a dia, e a necessidade de inserí-la no meio educacional para que os alunos aproveitem de uma aula mais interessante e muito mais dinâmica, tornouse cada vez maior. A tecnologia associada ao ambiente físico escolar possibilita a mudança da educação que passa a ser mais autônoma e centrada no aluno.

Os questionários aplicados durante e ao final da pesquisa abordaram questões relativas a conteúdos, abordagem educacional adotada, materiais usados, aspectos organizacionais, aspectos técnicos relativos ao uso da Internet, outras tecnologias empregadas e desempenho do profissional. As respostas foram obtidas por meio de uma combinação de diversos estilos de avaliação sendo questões abertas e fechadas.

Foram feitos teste de hipóteses, usando método U de Mann-Whitney para análise do comportamento das correlações entre as variáveis analisadas e o grau de explicação da variável dependente em relação das variáveis independentes da amostra. Após a tabulação dos dados coletados neste trabalho, foram exercidas 2 funções de análises estatísticas: descritiva e inferencial.

$\mathrm{Na}$ análise descritiva, foi traçado o perfil da amostra estudada, contemplando as variáveis analisadas e seus desdobramentos.

Os dados foram replicados de forma absoluta e relativas nesta primeira parte. Na estatística inferencial, foi traçado como objetivo estatístico, a análise de independência e predição entre as variáveis propostas no escopo do trabalho. Para isso, utilizou-se, dentro dos padrões esperados, o teste Mann-Whitney. Os resultados de independência entre as variáveis propostas, se deram pela análise entre os valores de $\mathrm{P}<0.005$ (significância). Todas as análises foram obtidas pelo Software SPSS Statistics (Versão 23) atreladas às funcionalidades da ferramenta Excel (versão 2016).

Foram utilizados os conceitos do Design Instrucional Contextualizado (DIC) e seu modelo ADDIE - acrônimo das fases descritas em inglês para Analysis (Análise), Design (Design), Development (Desenvolvimento), Implementation (Implementação) e Evaluation (Avaliação) (REIS et al., 2016; BERNARDO, 2017; LIMA et al., 2018; SIQUEIRA, 2019) para o desenvolvimento da disciplina e ambiente virtual de aprendizagem. 
Para flexibilizar o tempo de estudo e facilitar o processo de aprendizagem, todo o material de estudo foi disponibilizado em ambiente virtual de aprendizagem que poderia ser acessado em diferentes dispositivos conectados à internet, sejam eles móveis (Tablets, Smartphones e notebooks) ou não (computador de mesa).

\section{RESULTADOS}

O estudo mostrou que participaram inicialmente da amostra um total de 16 alunos da $2^{\mathrm{a}}$ e $3^{\mathrm{a}}$ séries do curso de graduação em Enfermagem inscritos no projeto de mestrado e que já tiveram um conhecimento prévio de Anatomia humana da série anterior, sendo que posteriormente, quatro alunos não desenvolveram as atividades propostas e foram identificados no estudo como "Missing”, pois deixaram de participar da pesquisa.

Quanto ao conhecimento do AVA, 75,00\% dos alunos disseram que conhecem o ambiente virtual de aprendizagem e que já realizaram algum tipo de curso ou disciplina EAD, pois $43,75 \%$ disseram ser de extensão ou de curta duração, enquanto, 56,25\% conheciam o Google Sala de aula, mas não o utilizavam em suas aulas.

De Acordo com o modo de acessibilidade dos alunos no Google Sala de Aula, a preferência de $50,00 \%$ dos alunos para o acesso ao ambiente virtual foi a utilização do notebook, ficando em segundo lugar o uso do smartphone, com 33,33\%. Na seguinte etapa, o dispositivo para acesso ao ambiente virtual de aprendizagem para download e leitura dos textos em PDF, conforme a preferência dos alunos foi de 50,00\% na utilização do notebook.

Em relação à participação nos fóruns de discussão referentes aos posts, "comentários no mural", a maioria $(58,33 \%)$ preferiu a utilização do smartphone para a interação com a ferramenta.

Numa escala de $100 \%$, quanto à preferência de dispositivo para a realização dos questionários objetivos do Google Sala de Aula, o smartphone ficou em primeiro lugar (58,33\%), enquanto a preferência para a realização dos questionários dissertativos, mais ad metade dos alunos preferiram o notebook $(66,67 \%)$. 
No que diz respeito ao questionário avaliativo e personalizado, referente ao ambiente virtual Google Sala de Aula, planejamento e metodologia de design instrucional aplicada, presente na Tabela 1,75,00\% dos alunos disseram que o acesso ao Google Sala de Aula e a organização do material didático foi satisfatória e muito satisfatória. Quando questionados sobre a distribuição das atividades ao longo da utilização do Google Sala de Aula e a qualidade das atividades quanto ao formato de questionários objetivos e dissertativos, 75,00\% dos alunos ficaram satisfeitos e muito satisfeitos, destacando que 4 alunos (25,00\%) que foram representados no estudo como "Missing" não participaram dessa etapa da pesquisa e não desenvolveram as atividades propostas, como mostra a Tabela 2. Conseguimos analisar nas Tabelas 1 e 2 a seguir, a participação dos alunos no questionário de design instrucional aplicada.

Tabela 1 - Análise do ambiente virtual, planejamento e metodologia do design instrucional aplicada. São José do Rio Preto, SP, Brasil, 2020

\begin{tabular}{ccc}
\hline ANÁLISE DO AMBIENTE VIRTUAL, & ORGANIZAÇÃO DO & ACESSO AO AVA \\
PLANEJAMENTO E METODOLOGIA DO & MATERIAL NO AVA & \\
DESIGN INSTRUCIONAL APLICADA & & $0,0 \%$ \\
\hline Muito insatisfeito & $0,0 \%$ & $0,0 \%$ \\
Insatisfeito & $0,0 \%$ & $0,0 \%$ \\
Nem satisfeito / nem insatisfeito & $0,0 \% \%$ & $25,00 \%$ \\
Satisfeito & $31,25 \%$ & $50,00 \%$ \\
Muito satisfeito & $43,75 \%$ & $25,00 \%$ \\
Missing & $25,00 \%$ & \\
\hline
\end{tabular}

Fonte: Própria autora.

Tabela 2 - Análise do ambiente virtual, planejamento e metodologia do design instrucional aplicada. São José do Rio Preto, SP, Brasil, 2020

\begin{tabular}{cccc}
\hline $\begin{array}{c}\text { ANÁLISE DO AMBIENTE } \\
\text { VIRTUAL, PLANEJAMENTO E } \\
\text { METODOLOGIA DO DESIGN } \\
\text { INSTRUCIONAL APLICADA }\end{array}$ & $\begin{array}{c}\text { DISTRIBUIÇÃO } \\
\text { DAS ATIVIDADES } \\
\text { NO AVA }\end{array}$ & $\begin{array}{c}\text { QUALIDADE DOS } \\
\text { QUESTIONÁRIOS } \\
\text { OBJETIVOS }\end{array}$ & $\begin{array}{c}\text { QUALIDADE DOS } \\
\text { QUESTIONÁRIOS } \\
\text { DISSERTATIVOS }\end{array}$ \\
\hline $\begin{array}{c}\text { Muito insatisfeito } \\
\text { Insatisfeito }\end{array}$ & $0,0 \%$ & $0,0 \%$ & $0,0 \%$ \\
Nem satisfeito / nem & $0,0 \%$ & $0,0 \%$ & $0,0 \%$ \\
insatisfeito & $0,0 \% \%$ & $0,0 \%$ & $0,0 \%$ \\
$\quad \begin{array}{c}\text { Satisfeito } \\
\text { Muito satisfeito }\end{array}$ & $56,25 \%$ & $25,00 \%$ & $25,00 \%$ \\
$\quad$ Missing & $18,75 \%$ & $50,00 \%$ & $50,00 \%$ \\
$\quad 25,00 \%$ & $25,00 \%$ & $25,00 \%$
\end{tabular}

Fonte: Própria autora.

$\mathrm{Na}$ análise do questionário de Autoavaliação do Google Sala de Aula, 62,50\% dos alunos relataram que a sua participação individual na ferramenta foi dentro do esperado, lembrando 
que dentre estes, apenas 4 (25,00\%) “Missing" não participaram dessa etapa da pesquisa, pois não desenvolveram as atividades propostas. Ao analisar se as metas estabelecidas foram alcançadas, 75,00\% responderam com assertividade que as metas foram atingidas. Quanto a importância do conteúdo exposto na ferramenta, 50,00\% dos alunos julgaram que foi maior do que o esperado, e a participação do grupo, na ferramenta, 43,75\% consideraram regular. Por fim, quanto a pertinência dos conteúdos para o ensino da Anatomia Humana, 56,25\% relataram maior que o esperado, como mostra a Tabela 3.

Tabela 3 - Autoavaliação do Ambiente Virtual de Aprendizagem - Google Sala de Aula. São José do Rio Preto, SP, Brasil. 2020

\begin{tabular}{lccccc}
\hline $\begin{array}{l}\text { Autoavaliação- Google } \\
\text { Sala de Aula }\end{array}$ & $\begin{array}{c}\text { Participação } \\
\text { Individual } \\
\text { no AVA }\end{array}$ & $\begin{array}{c}\text { As metas } \\
\text { foram } \\
\text { alcançadas }\end{array}$ & $\begin{array}{c}\text { Importância } \\
\text { do conteúdo }\end{array}$ & $\begin{array}{c}\text { Participação } \\
\text { do grupo no } \\
\text { AVA }\end{array}$ & $\begin{array}{c}\text { Pertinência } \\
\text { dos } \\
\text { conteúdos } \\
\text { para o } \\
\text { ensino de } \\
\text { Anatomia }\end{array}$ \\
\hline Menor que o esperado & $0,0 \%$ & $0,0 \%$ & $0,0 \%$ & $0,0 \%$ & $6,25 \%$ \\
Regular & $0,0 \%$ & $0,0 \%$ & $0,0 \%$ & $43,75 \%$ & $0,0 \%$ \\
Esperado & $62,50 \%$ & $37,50 \%$ & $25,00 \%$ & $12,50 \%$ & $12,50 \%$ \\
Maior que o esperado & $12,50 \%$ & $37,50 \%$ & $50,00 \%$ & $18,75 \%$ & $56,25 \%$ \\
Missing & $25,00 \%$ & $25,00 \%$ & $25,00 \%$ & $25,00 \%$ & $25,00 \%$ \\
\hline
\end{tabular}

Fonte: Própria autora.

Dos 16 alunos que aceitaram participar da pesquisa, apenas 12 desenvolveram as atividades propostas e interagiram com a ferramenta. Houve 41 post de mensagens interacionais no mural da ferramenta, na qual sete alunos completaram todas as atividades propostas, quatro não concluíram nenhuma atividade e foram identificados no estudo como "Missing" e cinco deixaram uma única atividade pendente.

Após a soma das notas relativas ao cumprimento do prazo para realização das atividades, a média total da turma, numa escala de 100, foi de aproximadamente 100, que pôde ser considerado um excelente índice de participação efetiva, comprometimento, distribuição e aproveitamento do tempo dedicado aos estudos.

Em relação à avaliação dos professores-tutores sobre a pertinência do conteúdo postado pelos alunos nas atividades realizadas, por se tratar de uma percepção subjetiva, intrínseca e peculiar individual do aluno e do professor-tutor, não foram consideradas as notas de aprovação dos discentes para o presente estudo. Porém, as notas de participação e 
realização das atividades no prazo foram úteis aos professores-tutores para analisar o empenho dos alunos com a disciplina.

E por fim, foi questionado se o aluno/colaborador considerava que o AVA é uma ferramenta importante para o ensino-aprendizagem de Anatomia Humana, especificamente, obtivemos $100 \%$ de assertividade.

\section{DISCUSSÃO}

A aplicação de ambientes virtuais de aprendizagem, como o uso da plataforma Google Sala de Aula, de forma coerente e responsável, demonstra ser uma forma eficiente de construir conhecimento, fomentar a autonomia, desenvolver habilidades, melhorar o seu discurso e sua capacidade de argumentação e trabalhar em conjunto com outros participantes, além de representar excelente oportunidade de capacitação profissional. (BOLLELA e CESARETTI, 2017).

Neste estudo, trabalhamos a discussão de casos clínicos com os alunos e debatemos sobre as atividades e resolução de problemas que sejam relevantes e que auxiliem na compreensão do conteúdo. Este presente estudo é semelhante a um realizado na USP de Ribeirão Preto, que fez uma breve revisão sobre uma estratégia educacional, mas diverge no contexto didático. Uma explicação para este fato, é que na USP a disciplina está na grade curricular e o professor mantém os encontros com seus alunos numa sala de aula, rotineiramente, reforçando ainda mais a sua prática. A disponibilidade de materiais que já se encontram presentes na internet facilita o ensino-aprendizagem como foi indicado neste trabalho, porém, uma divergência foi a priorização do preparo de vídeoaulas para o auxílio das aulas (BOLLELA e CESARETTI, 2017).

No nosso estudo, as atividades foram elaboradas na modalidade de fóruns e tarefas. Nos fóruns, ocorria a participação dos alunos no mural e eram discutidas questões problematizadoras e materiais de referência para consulta. Um trabalho realizado na universidade estadual da Paraíba e na Universidade de Pernambuco com alunos da PósGraduação em Enfermagem, na disciplina de Didática do Ensino Superior, também utilizou a ferramenta de atividades de aprendizagem colaborativa à distância, utilizando-se de uma 
carga horária maior e com mais aulas presenciais, divergindo do nosso estudo, no qual a população era de alunos de graduação, com objetivos diferentes e carga horária menor. Seguindo o modelo de outros estudos, a nossa pesquisa presentou a ferramenta no primeiro dia da aula presencial, em que foram especificados o objetivo, a usabilidade e o código para o acesso. Os alunos usaram o Mural para postagens, mas não para debates. Diferentemente de um estudo conduzido nos estados da Paraíba e Pernambuco, no qual os discentes participaram por meio de comentários e debateram o assunto com os demais colegas, contribuindo para uma aprendizagem mais colaborativa (LIMA et al., 2018).

No aspecto sobre a avaliação da disciplina, o presente trabalho também corrobora um estudo realizado na Paraíba e em Pernambuco, quanto à utilização da ferramenta para a comunicação e feedback entre professores e estudantes, na qual os professores elaboraram atividades, como tarefas aos alunos, e iniciaram instantaneamente debates com a turma, com os alunos compartilhando recursos uns com os outros e interagindo no mural da turma ou por e-mail. Os professores acompanharam se o aluno concluiu ou não a atividade proposta no prazo, deram feedback direto e em tempo real e atribuíram notas. O sistema de atividade ou postagem na plataforma gerou uma notificação direta no e-mail do aluno e no aplicativo Google Sala de aula. A avaliação da disciplina na ferramenta foi muito importante pois considerou, além do registro da participação do aluno no AVA, a sua assiduidade, a participação nas atividades e o trabalho em equipe (LIMA et al., 2018).

A utilização das TICs no processo do ensino-aprendizagem está cada vez mais em ascensão e mostra ambientes virtuais de ensino em saúde (AVAs), por meio da plataforma Google Sala de Aula, sendo utilizados em uma faculdade de medicina que corrobora um trabalho realizado pela faculdade de Medicina de Minas Gerais (UFMG), em 2015, que envolveu acadêmicos e docentes da instituição na aplicação de desafios clínicos inseridos na homepage da Faculdade de Medicina, contribuindo para a formação profissional de médicos e, parte das atividades avaliativas das disciplinas obrigatórias, como Anatomia Patológica, são realizadas por meio do ambiente virtual Moodle da UFMG para aprimorar o ensino na modalidade presencial. Esse trabalho diverge do nosso, no aspecto da utilização de provas escritas no Google Sala de Aula e por apresentar um público-alvo com um maior número de alunos participantes, no total de 61 discentes monitores das disciplinas obrigatórias referidas (REIS et al., 2016). 
A metodologia utilizada neste trabalho, usou a aplicação do Google Sala de Aula no ensino-aprendizagem de Anatomia. Após o encerramento do curso, foi aplicado um questionário composto de perguntas fechadas e algumas questões abertas para averiguar a opinião dos alunos a respeito da utilização do Google Sala de Aula. Um estudo realizado pelo Senac de Pernambuco, usou a mesma aplicação do Google Sala de Aula, porém, para o ensino da Língua Espanhola, como uma ferramenta instigadora para a aprendizagem como recurso tecnológico pedagógico com aplicabilidade de exercícios complementares no curso de espanhol. o propósito da metodologia aplicada pelo Senac foi o mesmo usado pelo presente estudo, ou seja, de coletar as informações para análise, reflexão e compreensão da relação dos alunos de língua espanhola ao uso do aplicativo Google Sala de Aula e os benefícios que possa trazer como ferramenta facilitadora da aprendizagem que corrobora este trabalho. A diferença foi apenas nas disciplinas ensinadas, Língua Espanhola versus Anatomia Humana e na população dos estudos. Os resultados apresentados também corroboram a eficácia do uso da ferramenta do Google Sala de Aula, como recurso tecnológico no processo de ensinoaprendizagem da disciplina, além de auxiliar no processo de desenvolvimento de habilidades de comunicação, criticidade e criatividade dos alunos, potencializando o uso de novas tecnologias dentro e fora da sala de aula.

Outra divergência, foi no tempo de aplicabilidade da ferramenta. $O$ tempo de aplicação do nosso estudo foi de apenas 30 horas/aula. Por ser uma disciplina regular do nível básico do curso de espanhol e contar com três turmas, a população foi composta por um total de 45 alunos participantes de diversas faixas etárias (BERNARDO, 2017).

Um estudo realizado na Cidade de Manaus pela Faculdade de Informação e Comunicação (FIC) da UFAM em que participou do estudo uma turma do sexto período do Curso de Bacharel em Arquivologia no segundo semestre de 2018, também utilizou a ferramenta no ensino-aprendizagem da disciplina de Tecnologias da Informação e corrobora este presente trabalho sobre a metodologia desenvolvida com a aplicação de um questionário final que verificou um percentual de 70\% dos alunos satisfeitos com essa metodologia pedagógica (SIQUEIRA, 2019), que converge com os achados deste estudo, no qual 75\% da população ficaram satisfeitos com a metodologia. Esse mesmo autor, relatou com relação à satisfação do material, que $60 \%$ da população ficou satisfeita com o conteúdo dos materiais disponibilizados pelo Google Sala de Aula, com resultado muito semelhante ao nosso, em que 
68,75\% disseram que os conteúdos propostos foram pertinentes para o ensino de Anatomia Humana. O autor relatou que, para 90\% dos alunos, a disciplina atendeu as expectativas quanto ao conteúdo abordado o que converge com $75 \%$ dos achados no nosso, no qual julgaram que as metas estabelecidas sobre o uso da ferramenta na disciplina de Anatomia Humana foram alcançadas neste presente trabalho.

Em comparação com um trabalho desenvolvido em Uberlândia, MG, a nossa pesquisa corrobora alguns aspectos, pois, os alunos gostaram das atividades desenvolvidas no Google Sala de Aula e o trabalho docente foi facilitado por meio da utilização do Google drive. No estudo citado, como no nosso, muitos alunos inscritos na pesquisa conhecem e alguns já fazem uso da tecnologia descrita, favorecendo o trabalho docente na correção das atividades. Portanto, o elo de interação professor/tutor e aluno mostrou-se eficiente (ARAÚJO, 2016).

Quanto ao desenvolvimento do ambiente virtual de aprendizagem, o método utilizado para este trabalho também vai ao encontro do trabalho desenvolvido em Uberlândia/ MG, em que ao trabalhar com o Google Sala de Aula na aplicação de atividades referentes ao ensino da Matemática, as TICs desenvolvidas pela professora foram as mesmas usadas no presente trabalho, ou seja, exercícios com questões de múltipla escolha e vídeo aulas disponíveis no Youtube, com a finalidade de criação de um ambiente interativo e dinâmico bem como agregar o trabalho em conjunto do professor/tutor e o seu aluno em tempo real (ARAÚJO, 2016).

Com base no estudo desenvolvido em Manaus, que também utilizou a ferramenta para o ensino de química no ensino médio, de uma escola pública, o presente trabalho corrobora em alguns aspectos os achados desse estudo quanto a avaliação do uso do Google Sala de aula pelos alunos. Dos 29 alunos presentes nas aulas de Química, apenas 19 tinham acessado e respondido a atividade proposta tão logo o questionário avaliativo foi aplicado (SILVA e FRANCISCO NETTO, 2018). Assim como este presente trabalho que possuía uma amostra inicial de público-alvo composta de 16 alunos e, durante o curso, ficaram 12 alunos participantes das atividades e respondentes do questionário avaliativo.

Quanto ao critério de avaliação da participação dos alunos no AVA, neste presente trabalho é possível perceber no Google Sala de Aula características didáticas, pois as respostas dos alunos se mantiveram entre "esperado" e "maior que o esperado" que converge com o estudo realizado na escola pública de Manaus com o ensino de Química que utilizaram as 
categorias, extremamente fácil, fácil e razoável, mas diverge quando somente 2 alunos de Manaus responderam ter achado difícil o acesso por não ter muito contato com computador (SILVA e FRANCISCO NETTO, 2018).

Com relação ao estudo realizado em Manaus, houve convergência com este presente trabalho, quanto ao questionário avaliativo do uso do Google Sala de Aula que avalia se o aluno conseguiu ter acesso ao conteúdo da disciplina rapidamente e se o conteúdo foi importante para o seu conhecimento. Foi considerado positivo quanto a rapidez no acesso à plataforma e a melhoria de seu entendimento sobre a disciplina (SILVA e FRANCISCO NETTO, 2018).

Neste trabalho, quando os alunos foram questionados se o Google Sala de Aula é uma ferramenta importante para o ensino-aprendizagem de Anatomia Humana, foi possível avaliar como foi vantajosa a associação desta ferramenta na prática docente da disciplina de Anatomia Humana, pela possibilidade dos profissionais realizarem exercícios que favoreceram a compreensão da disciplina e, consequentemente, a capacidade de se envolverem nas diversas situações de estudos de casos clínicos, gerando resultados satisfatórios, ou seja, para que sejam capazes de associarem pensamento, ação e bons resultados.

A escolha do Google Sala de Aula para a elaboração deste trabalho foi a gratuidade da ferramenta e o fácil manuseio, que permite a valorização da atuação do professor que se disponibiliza na maior parte do tempo à supervisão, o acompanhamento e à avaliação do aluno tornando a aprendizagem mais atrativa com interações que vão muito além de uma sala de aula.

Essas Tecnologias de Comunicação Digital (TCD) trazem muitos benefícios para os estudantes e docentes, que buscam complementar sua aprendizagem ou prática pedagógica, pois contribuem para romper com o protocolo das aulas tradicionais, onde os estudantes devem chegar a sala de aula e apenas receber as informações, como se fossem programados, similares a robôs. Porém, considera-se que o processo de aprendizagem decorre das interações com o objeto de conhecimento, sendo o trabalho colaborativo e cooperativo fundamental para a aprendizagem (ROSENAU, N. R. et al., 2017). 
A interatividade da ferramenta deverá ser planejada previamente para que as interações ocorram com clareza e intenção educacional. Atualmente dentro da escola há muita resistência quanto ao uso de tecnologias, muitos profissionais não simpatizam com a evolução das Tecnologias de Comunicação Digital (TCD) no mundo, e alguns destes profissionais não aceitam as novas tecnologias em sala de aula acreditando que seu método tradicional é suficiente. Considera-se que as Tecnologias de Comunicação Digital (TCD) podem mudar a educação tradicional, trazendo benefícios para os estudantes e docentes, além das facilidades para a comunicação é possível também assistir a vídeos educativos, documentários, videoaulas e pesquisas científicas em qualquer lugar (Rosenau, 2017).

O Google Sala de Aula possibilita um maior contato do professor e estudante, como também a colaboração entre estudante com estudante. $O$ foco da aula está na aprendizagem do estudante que se percebe como parte da turma quando é atendido em suas dificuldades, seja pelo professor ou pelos próprios colegas que tem mais facilidade. Fato que corroborou com um aumento no engajamento dos estudantes nas aulas de matemática (SCHIEHL, E. P.; GASPARINI, I., 2016)

As limitações encontradas no desenvolvimento desta pesquisa, dizem respeito à dependência do professor/tutor confiar na execução das atividades propostas aos alunos que foram desenvolvidas mediante à sua disponibilidade de tempo, de sua boa vontade e de sua persistência para que não comprometessem os resultados esperados com a organização e elaboração e dos conteúdos no Google Sala de Aula. Outra limitação importante foi que, apesar de existirem diversas faculdades de enfermagem na região, nenhuma permitiu que a pesquisa fosse realizada com seus alunos. Inclusive, na faculdade campo de estudo, a coordenadora da disciplina de Anatomia Humana, não permitiu que a pesquisa fosse realizada com os alunos cursantes. Para que a pesquisa fosse realizada, os professores precisaram oferecer a disciplina como extracurricular e houve uma baixa adesão dos alunos.

\section{CONCLUSÃO / CONSIDERAÇÕES FINAIS}

Esta pesquisa utilizou a ferramenta Google Sala de Aula no sistema superior de ensino como apoio ao ensino-aprendizagem e pudemos constatar que os alunos se transformaram 
em produtores de seu próprio conhecimento, e que compartilharam com os demais colegas e com o professor/tutor experiências que garantiram a interação entre os participantes, em tempo e espaço variados. Como implicação para a prática, esta pesquisa mostrou que, a implementação de uma plataforma on-line, utilizada no ensino superior, tendeu a despertar o interesse dos alunos pela disciplina estudada, pois com a flexibilidade de horários para o desenvolvimento das atividades, o aluno não ficou dependente de uma sala de aula para a concretização de seu estudo e tornou possível aprimorar o processo de ensino-aprendizagem de forma mais colaborativa e efetiva.

Os resultados decorrentes da análise quantitativa, permitiram concluir que a construção do conhecimento pôde ser incrementada pela união de estratégias de ensino que permitaram a autonomia e criticidade dos alunos, a relação dialógica e aprofundamento dos conteúdos. O Google Sala de Aula, segundo os alunos de Enfermagem participantes da pesquisa, foi uma ferramenta importante para o ensino-aprendizagem de Anatomia Humana, pois possibilitou avaliar como foi vantajosa a associação dessa ferramenta na prática docente da disciplina de Anatomia Humana, pela possibilidade de os futuros profissionais realizarem exercícios que favoreceram a compreensão da disciplina e, consequentemente, a capacidade de se envolverem nas diversas situações de estudos de casos clínicos, gerando resultados satisfatórios, ou seja, para que sejam capazes de associarem pensamento, ação e bons resultados. Diante do exposto, pudemos observar que a ferramenta Google Sala de Aula possibilitou mesclar a sala de aula tradicional com recursos digitais, pelos quais o aluno pôde estudar em uma sala de aula virtual, em seu próprio ritmo. Além disso, ofereceu um rápido feedback, ou seja, todos os componentes usados para verificar a aprendizagem precisaram reagir aos resultados obtidos pelos alunos em uma determinada atividade.

A utilização da ferramenta Google Sala de Aula permitiu aos alunos uma maior flexibilidade para estudar em momentos on-line, por meio de um computador ou smartphone, bem como em momentos presenciais com a mediação de um professor e a interação com os colegas.

É essencial que as instituições de ensino ofereçam aos professores cursos de capacitação e divulgação dos recursos tecnológicos aliados às metodologias de ensinoaprendizagem ativas para promoverem uma formação que atenda às necessidades de uma sociedade em constante transformação. 


\section{REFERÊNCIAS}

ARAÚJO, H. M. C. O uso das ferramentas do aplicativo “Google Sala de Aula" no ensino de Matemática. 2016. 93 f. Dissertação (Programa de Mestrado Profissional em Matemática) - Universidade Federal de Goiás, Catalão, 2016. Disponível

em: https://pdfs.semanticscholar.org/ba09/04d3fde03fd3650612378fcd5f2ea446a0db.pdf. Acesso em: 09 mar. 2020.

BACHIC, L.; TANZI NETO, A.; TREVISANI, F. M. (org.). Ensino Híbrido: personalização e Tecnologia na Educação. Porto Alegre: Penso, 2015.

BERNARDO, S. F. Contribuições do Google Sala de Aula para o ensino de idiomas: relato de experiência. In: CONGRESSO INTERNACIONAL DE TECNOLOGIA NA EDUCAÇÃO, 15., 2017, Recife. Anais [...]. Recife: Cubo 9 Agência Digital, 2017.p. 1-14.

BOLLELA, V. R.; CESARETTI, M. L. R. Sala de aula invertida na educação para as profissões de saúde: conceitos essenciais para a prática. Revista Eletrônica de Farmácia, Goiânia, v. 14, n. 1, p. 39-48, jan./dez. 2017. Disponível em: https://www.revistas.ufg.br/REF/article/view/42807/pdf. Acesso em: 09 mar. 2020.

BORGES, T. S.; ALENCAR, G. Metodologias ativas na promoção da formação crítica do estudante: o uso das metodologias ativas como recurso didático na formação crítica do estudante do ensino superior. Cairu em Revista, Salvador, v. 3, n. 4, p. 119-143, jul./ago. 2014.

DIAS, F. A. O. O papel das tecnologias da informação e comunicação (TIC) no cumprimento das metas do plano nacional da educação (PNE). Revista de Pesquisa Interdisciplinar, Cajazeiras, n. 2, p. 1-11, set. 2017. Suplemento. Disponível em:

http://revistas.ufcg.edu.br/cfp/index.php/pesquisainterdisciplinar/article/view/216/pdf. Acesso em: 09 mar. 2020 .

FUNDAÇÃO TELEFÔNICA VIVO. Experiências avaliativas de tecnologias digitais na educação. São Paulo, SP: Fundação Telefônica Vivo, 2016. Disponível em: http://fundacaotelefonica.org.br/wpcontent/uploads/pdfs/experiencias_avaliativas_portugues.pdf. Acesso em: 09 mar. 2020.

GALVÃO, A. P.; THOMAS, A.; PEREIRA, P. M. P. O uso das TIC na Educação Superior: estudo de caso com Docentes de áreas sociais de uma IES do Oeste do Pará. In: ENCONTRO VIRTUAL DE DOCUMENTAÇÃO EM SOFTWARE LIVRE, 14.,/ CONGRESSO INTERNACIONAL DE LINGUAGEM E TECNOLOGIA ONLINE, 11., 2017. Anais [...]. Belo Horizonte: SEMIOTEC, 2017. Disponível em: http://www.periodicos.letras.ufmg.br/index.php/anais_linguagem_tecnologia/article/view/12104. Acesso em: 10 mar. 2020.

LIMA, M. C. V.; LISBÔA, G. L. P.; AQUINO, J. M.; SILVA, M. A. S. Uso do aplicativo google classroom em disciplina de pós-graduação em enfermagem. In: V CONEDU CONGRESSO NACIONAL DE EDUCAÇÃO, 5., 2018, Olinda. Anais [...]. Olinda: CONEDU, $2018 . \quad$ Disponível em: http://www.editorarealize.com.br/revistas/conedu/trabalhos/TRABALHO_EV117_MD1_SA2_ID8059_1709201 8170643.pdf. Acesso em: 09 mar. 2020.

MOURTHÉ FILHO, A. et al. Refletindo o ensino da Anatomia Humana. Enfermagem Revista, Minas Gerais, v. 19, n. 2, p. 169-175, jul./dez. 2016.

OLIVEIRA, W. A.; COPPOLA, N. A importância das metodologias ativas na formação do enfermeiro no Brasil. Revista de Saúde, Brasília, v.4, n.2, p. 59-75, ago./dez. 2017. Disponível em: http://revista.faciplac.edu.br/index.php/RSF/article/view/409/188. Acesso em: 09 mar. 2020.

REIS, Z. S. N. et al. Tecnologias digitais para o ensino em saúde: relato de experiências e a convergência para o projeto AVAS21. Revista de Saúde Digital e Tecnologias Educacionais, Fortaleza, v. 1, n. 1, p. 69-76, jan./jul. 2016. Disponível em: http://periodicos.ufc.br/resdite/article/view/4685/3488. Acesso em: 09 mar. 2020.

ROSENAU, N. R. et al. As tecnologias de comunicação digital como recurso pedagógico na escola. In: SEMINÁRIO INTERNACIONAL DE REPRESENTAÇÕES SOCIAS, SUBJETIVIDADE E EDUCAÇÃO - SIRSSE, 4./ SEMINÁRIO INTERNACIONAL SOBRE PROFISSIONALIZAÇÃO DOCENTE (SIPD/CATEDRA UNESCO), 6. , 2017, Curitiba. Anais 
[...]. Curitiba: EDUCERES, 2017. p. 14292-14304. Disponível em: https://educere.bruc.com.br/arquivo/pdf2017/24126_12788.pdf. Acesso em:09 mar. 2020.

SCHIEHL, E. P.; GASPARINI, I. Contribuições do Google Sala de Aula para o ensino híbrido. revista renote: Novas Tecnologias na Educação, v. 14, n. 2, 2016. Disponível em: https://doi.org/10.22456/16791916.70684. Acesso em: 02 mar. 2021.

SILVA, A. R., et al. Anatomia Digital: um Ambiente Virtual de Apoio ao Processo Ensino-aprendizagem. In: VI Congresso Brasileiro de Informática na Educação (CBIE 2017), 6./ SIMPÓSIO BRASILEIRO DE INFORMÁTICA NA EDUCAÇÃO (SBIE 2017). 28., 2017, Porto Alegre. Anais [...]. Porto Alegre: Sociedade Brasileira de Computação, 2017. p. 745-755. Diponível em: https://br-ie.org/pub/index.php/sbie/article/view/7603/5399. Acesso em: 09 mar. 2020.

SILVA, G. M. L.; FRANCISCO NETTO, J. Um Relato de Experiência Usando Google Sala de Aula para Apoio à Aprendizagem de Química. In: CONGRESSO BRASILEIRO DE INFORMÁTICA NA EDUCAÇ̃̃̃O, 7., WORKSHOP DE INFORMÁTICA NA ESCOLA, 24., 2018, Fortaleza. Anais [...]. Fortaleza: Sociedade Brasileira de Computação, 2018. p. 119-128. Disponível em: https://pdfs.semanticscholar.org/9cfb/0a655258d5e798361a2c37e9444c735d136e.pdf. Acesso em: 10 mar. 2020.

SIQUEIRA, T. G. S. Uso do google sala de aula no ensino superior: aceitação no processo educativo. Revista Brasileira de Educação em Ciência da Informação, São Cristovão, SE, v.6, n.1, p.54-62, jan./jun. 2019. Disponível em: https://brapci.inf.br/index.php/res/v/125549. Acesso em: 09 mar. 2020.

SOUSA JÚNIOR, A.; OLIVEIRA, C.; BRAGA, E.; LIMA, V. A. de. Google Suite for education: trazendo o Google Classroom como uma perspectiva para as salas de aula usando os dispositivos móveis. In: CONGRESSO SOBRE TECNOLOGIAS NA EDUCAÇÃo, 2, 2017. anais... João Pessoa: CTE, 2017. Disponível em: http://ceur-ws.org/Vol1877/CtrlE2017_AC_11_19.pdf. Acesso em: 3 mar. 2021.

\section{$(\mathrm{cc)}) \mathrm{EY}$}

Este trabalho está licenciado com uma Licença Creative Commons - Atribuição 4.0 Internacional. 